\section{Practical Theorization vs Architectural Practice in OMA /AMO}

\section{Belén Butragueño}

Universidad Politécnica de Madrid

Javier Fco. Raposo

Universidad Politécnica de Madrid

\section{Mariasun Salgado}

Universidad Politécnica de Madrid

\section{INTRO}

In the last years, there has been a disengagement between practicing architects and scholarship profiles. At present, there is a clear divergence between theory and practice in architecture. Theorization has been confined in Universities and Schools of Architecture, that have also abandoned the architectural practice or the practical research, in many cases due to a lack of resources. At the same time, studios working on architectural "production", have not developed the necessary theoretical processes that could support their activity, as they are usually immersed in a frenetic activity allowing no remaining time for any kind of reflection on theoretical subjects.

We can find many reasons for that disengagement, that has been largely accelerated in the last ten years by the global economic crisis, with serious consequences for our professional field and the academic sphere.

\section{HISTORY}

In the past, the traditional education in Architecture was strongly focused on construction, being the built object the fundamental final goal.

The notion of "knowledge through doing" was introduced by Vitruvius, and adopted by many others to follow. As an example, eight of the "Ten books on Architecture" ("De Architectura", Marcus Vitruvius Pollio, 30-15 BC), were dedicated to building materials, civic infrastructure, civil engineering and technology and building types. The vision of architecture was based on experimental making and crafting (1). His fundamental contribution was the identification of three principles of architecture: "firmitas, utilitas, venustas", conventionally translated as "structural integrity, utility, and beauty"; or (Wotton, 1624) "firmness, commodity, and delight". These principles were considered as imperative for architectural theorists and practitioners during the next centuries. Vitruvian influence on subsequent architectural theories is undeniable and it's in the origin of architectural theory as a discipline, launched in the Renaissance by Leon Battista Alberti (2) with "De Re Aedificatoria" (1485). As indicated in the title, construction was yet the principal goal of architecture. The discussion over the next centuries run around the "honesty of the structure" (Ruskin, 1849), the fidelity to materials and construction (Otto Wagner, 1896) or the role of ornament in architecture. This last topic was specially discussed by functionalists as Sullivan (1896), author of the famous motto "form ever follows function".

The case of the Bauhaus deserves a special mention. The school emerged in 1919, under the direction of Walter Gropius, aiming to reunite fine art and functional design, to create practical objects with the soul of artworks. The School was deeply concerned with the combination of intellectual and theoretical approaches, that had a great impact on design. The Bauhaus was undoubtedly, the most influential art school of the 20th century, especially in Europe and USA, due to its approach to teaching, and the relationship between art, society, 
and technology. The unity between fine art and functional industrial design was its most important and original achievement. Regarding the relationship between practice and theory, there was a strong commitment with the sceintific and theoretical approach given to the design process, emphasizing the experimentation and problem-solving, both in art and architecture (Figure 1).

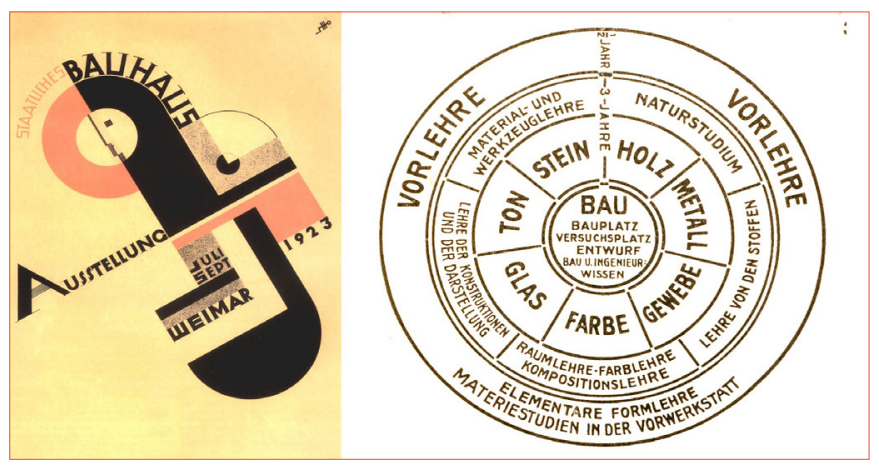

Figure 1. Poster, J Schmith, 1923 / Bauhaus Program, W. Gropius, 1925.

By that time, in Russia, a similar process was arising. The Vkhutemas (Higher Art and Technical Studios) emerged as a very influential artistic and industrial movement, attached to the Faculty. They were key in the development of three major movements in Avant Garde art and architecture: constructivism, rationalism, and suprematism. Vkhutemas was the Russian state art and technical school founded in 1920 in Moscow. The intention of the Soviet government was to prepare master artists of the highest qualifications for industry, and builders and managers for professional-technical education.

The two schools were among the first to train artist-designers in a modern manner, being both of them state-sponsored initiatives to merge the craft tradition with modern technology. Eve though Vkhutemas was a larger school than the Bauhaus, it was less familiar in Europe and USA. Thanks to the 1925 Exposition in Paris, where the work of El Lissitzky was exhibited, they became progressively more influential (Figure 2).
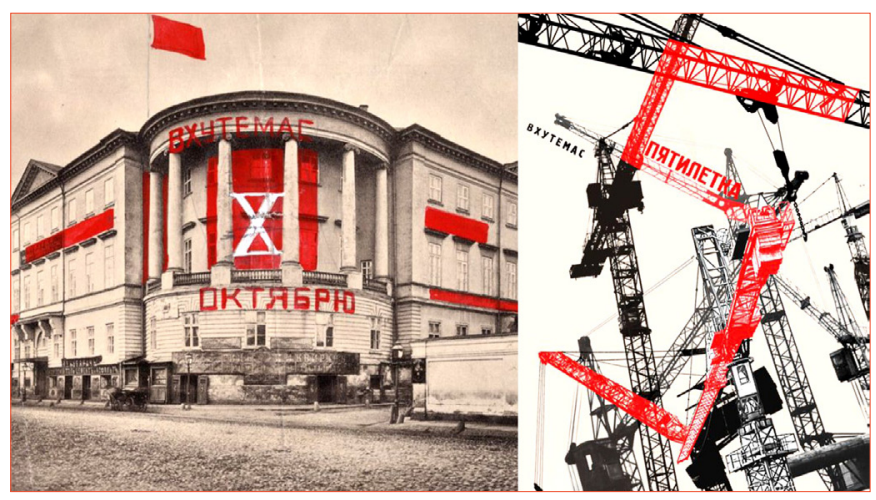

Figure 2. Vkhutemas School, 1925 / Vkhutemas Poster, 1920.
Later on, Radical Architectural Pedagogies played a crucial role in shaping the architectural discourse and practice of the second half of the 20th century. These movements intended to challenge the status quo by attempting to destabilize the institutions they depended on. It happened in 1968 at the Unité Pédagogique No 6 in Paris, which rejected the pedagogy of the Beaux-Arts School and, again one year later at Yale University. They thought that the school's curricula and teaching methods were incapable of addressing architecture's relationship to contemporary social and political concerns, and demanded to include them in the very basis of their studies. Many of their proposals had a real impact on Architectural Education and introduced a utopian perspective on results.

The subsequent steps taken by institutions, such as The Boyer Report (1996) in USA and the Bologna Declaration (1999) in Europe defined the architectural education as an academic discipline, based on research. The Boyer Report acknowledged the importance of research for academic advancement and encouraged institutions to address changes that allowed bigger achievements on that field. In the same way, the Bologna Process (1998), developed to enhance the quality and recognition of European higher education systems and to improve the conditions for exchange and collaboration within Europe, established research as the basis of the architectural education. This fact, definitely broke the traditional balance between theory and practice in architectural education and generated a progressive separation between these two branches.

\section{FAMOUS THEORETICAL-PRACTICING PROFILES}

At an individual level, we can find examples of renown architects that have approached their architectural practice from a theoretical perspective.

Probably, the figure that better represents the paradigm of the confluence between practice and theory is the Swiss architect Le Corbusier (1887-1965). He defined the principles of Modern Architecture and his vision of the city of the future, through his theoretical works, that soon became referential ("Vers une Architecture", 1923; "L'Esprit Nouveau", 1925; "The city of tomorrow", 1929) and he implemented them through his built heritage (Figure 3).

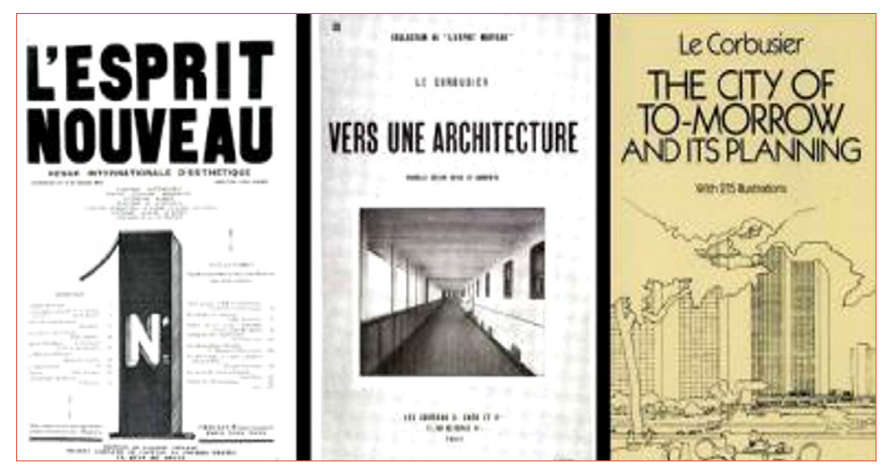

Figure 3. Le Corbusier's referential books. 
The tendency over time has been to integrate insights from a different discipline in the architectural practice, such as literary theory (Eisenman 2004; Wigley 1993) or continental philosophy (Pallasmaa 2005; Vesely 2004); information theory and computer science (Mitchell 1990); sociology (Lefebvre 1970 and 1974); urban studies (Krier 2009; Koolhaas 1978); cultural studies (Rapoport 1969; Oliver 1969); and science studies (Pérez-Gómez 1983). The architectural practice is progressively becoming an interdisciplinary endevour, with a strong weight of theoretical disciplines on its core.

In recent times, we can state that the Dutch Architect Rem Koolhaas has become one of the most representative examples of the so called "theoretical practice", being constantly compared with his predecessors. His design methodology requires, by principle, a deep previous theorization and the ulterior translation of the results into practice, which includes communication and "design of information"..

\section{OMA/AMO DICHOTOMY}

Rem Koolhaas founded OMA (Office for Metropolitan Architecture) in 1975 and, from the beginning, the team exhibited extremely controversial proposals that had a great influence on the architectural panorama and soon became referential works. However, they confronted strong difficulties to, ultimately, materialize their designs. In the decade of the 90's, OMA took part in several international competitions such as the "Tres Grande Biblioteque" (Figure 4) or Zeebrugge. Their proposals represented highly interesting exercises whose abstract and theoretical approach, that soon positioned them in the international scene. But these projects were considered a failure in practical terms, as none of them were awarded with a first prize and, consequently, they were not materialized. These "big scale" competitions had a high cost in terms of time and resources and the huge intellectual effort was not rewarded. They were forced to acknowledge the existing gap between theoretical (but extremely suggestive) architectural proposals and "competition-winning" proposals.

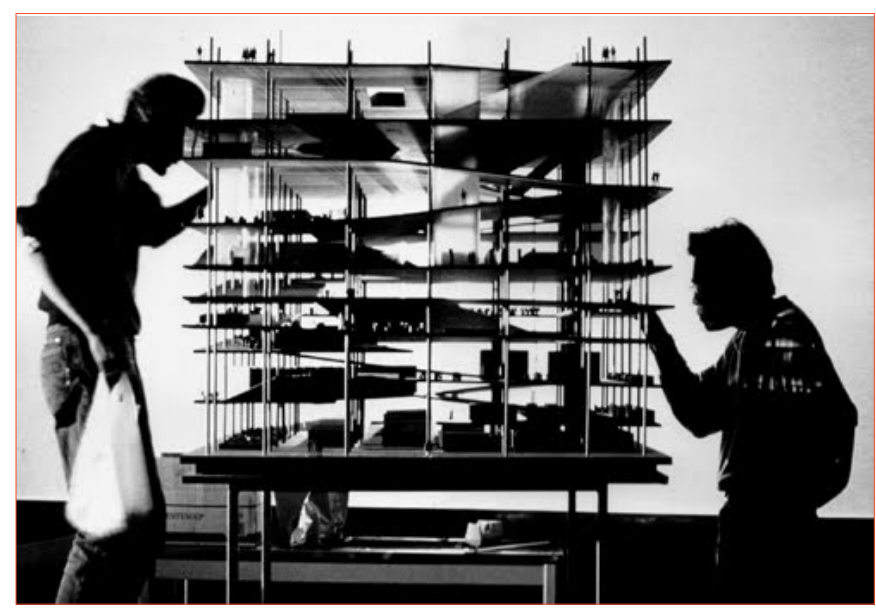

Figure 4. Deux Biblioteques Jussieus, OMA, 1927
This situation confronted OMA with a dichotomy: they had the need to materialize their proposals but they didn't want to give up on their theoretical approaches. In 1999, Rem Koolhaas and Dan Wood (OMA's partner since 1994) arrived to the idea of creating a merely speculative entity that worked alongside OMA, that exclusively followed their own internal agenda. In the article "Almost Famous" (Content, Ed. Taschen, 2004), Wood described the reasons for the foundation of $\mathrm{AMO}$, in a moment were the office was going through a deep conceptual and economic crisis, that forced them to undertake profound changes in the structure of OMA and its internal configuration. On the other hand, OMA was gaining international recognition thanks to the publication of the book "S.M.L.XL." (Monacelli Press, 1995), which meant the biggest success in the history of architectural publications (3). The book became a fetish object and a reference for anyone involved with architecture. OMA understood that it was an appropriate moment for creating this parallel institution.

In an interview (Index Magazine, 2000) with Jennifer Sigler, editor of "SMLXL", described the process as follows: "The book ("SMLXL") was published at a moment of serious crisis in our office, so everything that happened since is part of the construction of a new office, the construction of a new way of looking at architecture that culminated in the founding of AMO. AMO doesn't stand for anything specific, but it could be Architecture Media Organization. OMA and AMO are like Siamese twins that were recently separated. We divide the entire field of architecture into two parts: one is actual building, mud, the huge effort of realizing a project; the other is virtual - everything related to concepts and "pure" architectural thinking. The separation enables us to liberate architectural thinking from architectural practice. That inevitably leads to a further questioning of the need for architecture, but now our manner of questioning has changed: first we did it through buildings; now we can do it through intellectual activities parallel to building" (4).

Therefore, AMO was established as a parallel and independent entity from OMA, that could focus on pure theoretical subjects, regardless a previous commission or any engagement to the conditions of the market. AMO could be engaged in speculative research and pure experimentation, so that its agenda would be shaped with internal interests in mind, and not external events. Free from the imperative weight of building the architectural object, it is possible to find efficient and accurate solutions, with faster and more flexible means. In OMA's website we can find this description: "While OMA remains dedicated to the realization of buildings and master plans, AMO operates in areas beyond the traditional boundaries of architecture, including media, politics, sociology, renewable energy, technology, fashion, curating, publishing, and graphic design. AMO often works in parallel with 
OMA's clients to fertilize architecture with intelligence from this array of disciplines."

Certainly, OMA and $\mathrm{AMO}$ are not strangers to each other, they are related and interdependent. In certain occasions, they work in parallel and converge, as in the Prada Foundation projects. AMO usually investigates aspects related with identity, technology, materials and new production possibilities in the world of fashion, whereas OMA works on the architectural design of the new flagship stores for Los Angeles or New York and the Prada Foundation in Milan, applying AMO's findings.

In conclusion, AMO allows OMA to wean their intellectual concerns from the need to build, turning to purely speculative and theoretical experimenting lines. This tool enables the coexistence and interaction of theory and practice, escaping from the fleetingness of globalization. AMO was, at the same time, a determined attempt to open the interest on architectural topics to a wider audience, by addressing the problems that actually matters to our society, with no previous commission needed. The main idea is to bypass the intermediate entities and work directly with the final costumer.

From the perspective of the role of theorization in architectural practice, it is indeed very eloquent the need to split the office in two, in order to meet the expectations of both fields.

\section{PRACTICAL THEORIZATION}

In his article "Thinking and doing" ("Content", ED. Taschen, 2004), Rem Koolhaas makes a meaningful comparison between the manifestos addressed in the Twentieth Century and the current urban development in the World (Figure 5).

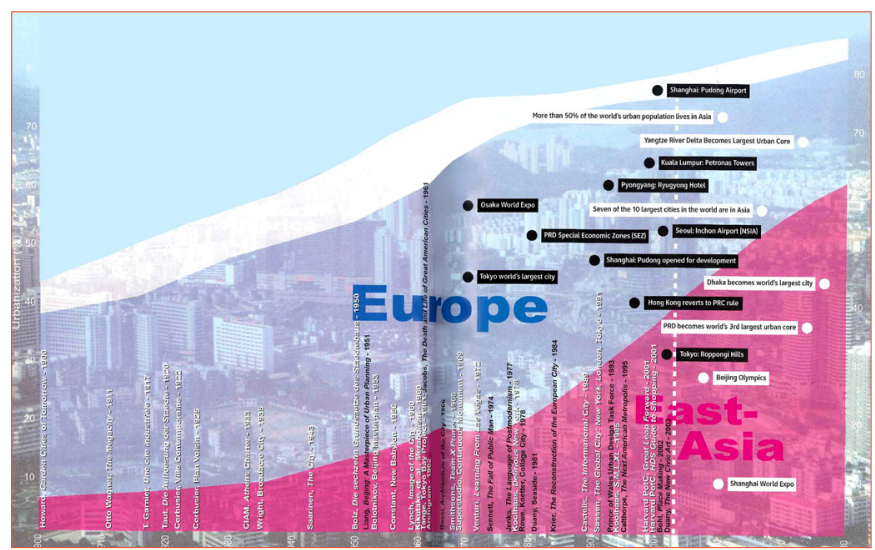

Figure 5. Diagram "Thinking Architecture", Content, OMA-AMO, 2004

The analysis of those data lead to very important conclusions. First, it is noticeable that the architectural theorization has been developed basically in Europe and North America whereas the most intense and important urban developments of the last years have been undertaken in Asia. Secondly, the researching and theoretical activity has radically declined since 1970 , whereas the urban activity has exponentially increased since that date. An in-depth analysis of these two parallel circumstances, perfectly reflects the increasing gap between the theoretical and the practical activity in architecture. The article reflects a deep concern on the fact that this hectic pace of construction in Asia, is lacking an intellectual support: "Asia is modernizing at three times the speed of its predecessors. Urbanization doubling every 20-30 years, but Europe and America are no longer thinking - not for themselves, not for others. We export the two most sterile outcomes of the vertical and the horizontal- the skyscraper and the "themed" (often gated) suburb - and witness Asia's urbanization with cruel smugness. The final chapter of modernization is taking place in an intellectual void partly of our making..." (5)

Regarding the theoretical activity, Rem Koolhaas argues that the architectural theory has been abandoned. He considers "Complexity and Contradiction in Architecture" (Robert Venturi, 1966) and "Learning from Las Vegas" (1972) as the last big manifestoes on architecture. In this second book, Venturi explains that the Modern Movement stripped the architecture of its communicative essence and had a significant influence on the architecture of the 20th century, creating a "burnt land" scenario $(6,7)$. In Koolhaas 'opinion, Venturi's manifesto opened a "space for a possible architecture" beyond the Modern Movement. He considers that, since then, there has been no in-depth reflection on the processes, media and content for which the built environment can issue information to the user, nor on the mental processes that provide information to the image that develops a building, or the implications of such perception in that image's construction. He concludes that the architectural mechanisms of representation have not been explicitly analyzed since the Modern Movement and argues that it is necessary to review that approach, understanding the double condition of architectural communication: the built element and the architectural narrative.

This reflection can be applied to the architectural theorization, which revitalization went hand in hand with the emergence of radical post-modern movements and groups (such as Archigram, Superstudio or the Situationists) with a highly theoretical activity. It progressively led to the cloistering of theorization in the Schools of Architecture and to the exacerbation of the gap between practicing architects and scholar profiles. At present, there is a clear divergence between theory and practice in architecture. Theorization has been confined in Universities and Schools of Architecture, that have also abandoned the architectural practice or the practical research, in many cases due to a lack of resources. At the same time, studios working in architectural "production", have not developed the necessary theoretical processes that could support their activity, as they are usually immersed in a frenetic activity and there is not any remaining time for reflection on theoretical subjects. 


\section{ARCHITECTURAL NARRATIVE}

Offices like OMA, that incorporate theorization in the architectural processes, resort to specific tools, such as the "architectural narrative". The narration and registration of the design processes has become an essential part of the creative cycle. OMA is said to issue one publication per day. Most of them have a domestic nature, in the majority of the cases they don't even reach the client. They work as an internal record to promote the assimilation of ideas, while inventorying them. In addition, the archive is an inspirational and referential tool, as is constantly revisited in order to bring light into new designs. A very characteristic example of this self-recycling strategy is the project of "Casa da Música" in Porto, that departs from a previous design of a house in Rotterdam (Y2K, 1998).

The extensive publishing production of OMA/AMO is perfectly illustrated by the exhibition "OMA Book Machine", curated by Brett Steele and Zak Kyes in 2010 at the Architectural Association of Architecture of London. The exhibition showed the work developed by Beatriz Colomina's students at Princeton University consisting in the creation a mega-book of more than 40,000 pages that gathered most of the books, pamphlets and publications of all kinds that OMA had developed since 1978 (Figure 6). The "colossal" result contained all OMA's conceptual construct and its history and gave a dimension of the importance of theorization for this office.

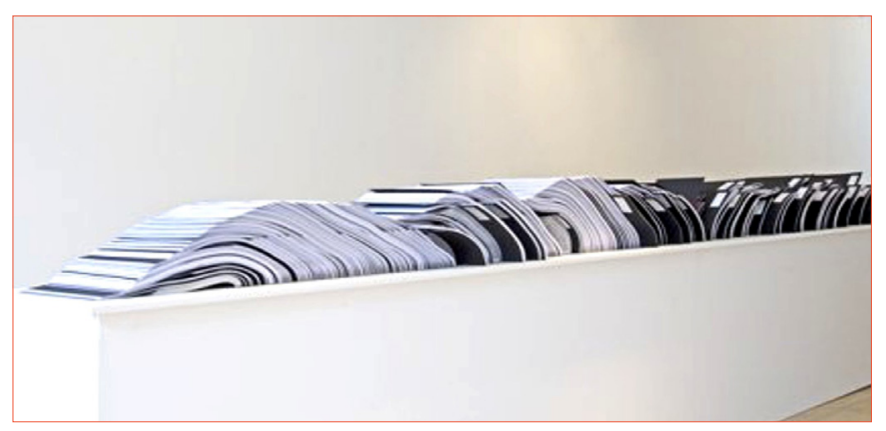

Figure 6. Exhibition "OMA Book Machine", Architectural Association, 2010.

In recent years, OMA's Archive has become a fundamental part of the office. It started as a casual and chaotic storage room close to the kitchen, but since the year 2000, it is being used as a constant referential resource. It contains more than 10.000 works on paper and more than 3.000 boxes with models, samples and other objects. They were inventoried at the initiative of Aaron Betsky (NAi, National Architecture Institute, Rotterdam), in 2001, who suggested the possibility to buy it and exhibit it. However, the office decided to address the problem and hire an historian as the Head of Archive to have a precise control of the content, in order to use it as a query tool. Koolhaas understood that outsourcing these documents meant disregarding an essential feature of the creative processes in OMA/AMO.

Beatriz Colomina discussed this topic with Rem Koolhaas in an interview published at El Croquis ("The architecture of publications", 2007), where we can find a diagram (Figure 7) that visualizes the exponential growth of the publishing activity in OMA from 1975 to 2007 (El Croquis, 2007) which intensity is increasingly growing nowadays.

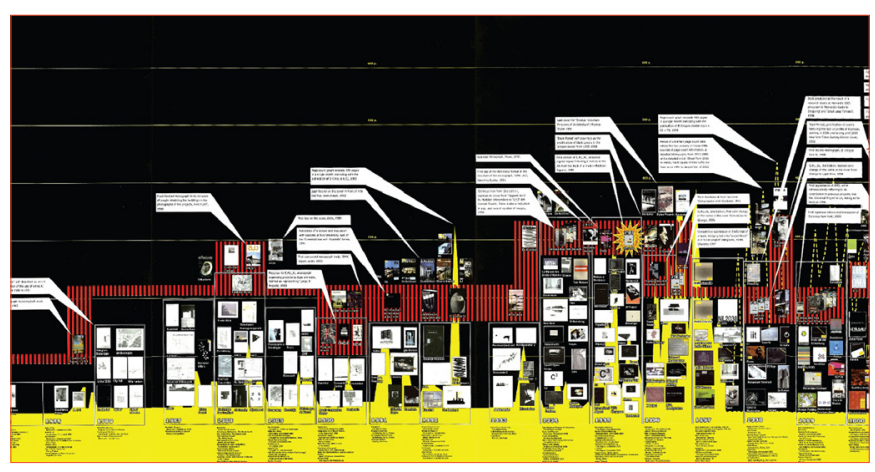

Figure 7. Diagram "The Architecture of Publications". B. Colomina, 2007.

The dimension of this activity brings us to address the complexity of the data managing process and introduces the concept of "design of information".

\section{DESIGN OF INFORMATION}

When discussing the consequences of the emergence of $\mathrm{AMO}$ as a separate institution, we can conclude that its first achievement was to introduce the theorization both in the architectural practice and in the communicative strategy. A deep analysis of this strategy and the management of the information, has allowed us to extrapolate it to the state of the art of research and design, beyond the figure of Rem Koolhaas. This subject is playing a decisive role in the current development of architecture, with a growing influence in the initial stages of the project or the theoretical developments. It allowed us to determine that there is a deeply positive confluence and feedback between both disciplines: architecture and architectural research. The inclusion of the record (and not only as its completion) as part of both the design process and the researching process, has allowed an exponential growth of experimentation and creativity and enabled the positive data interchange between them.

Rem Koolhaas introduced the term "Design of Information" to highlight the importance of the communicative approach in the design process and how the strategies followed to transmit the projects may vary the perception of the audience (8). About the different factors affecting the communication process, authors like Greg Bateson ("Steps to an Ecology of Mind,", 1972) suggests that the essence of the communicative act is the creation of redundancy or an apprehended pattern that adds a degree of predictability to the message (9). Therefore, the goal is no to decode a message through a language, but to create a context that generates partial and fragmented interpretations that expand the significance of the object. When applying this theory to the graphic communication, the main factors are the message, the graphic code and the context, placing the burden in the 
last two concepts. The design of the Information is as important as the information itself, in order to accurately communicate the desired message and even to transform it.

OMA's most relevant books are perfect examples of this statement. The book "SMLXL", that meant a milestone in architectural communication, is also one of the most representative examples of the confluence between theory and practice. The book showed alternative approaches to well-known projects, encouraging a different understanding and a wider comprehension of them by the audience. His next high-impact book, "Content" (Ed. Taschen, 2004) took one more step: the manipulation of the communicative codes to the limits, leading to the creation of a new genre in the field of architectural monographies. Being a book with an ambiguous format, (between a book and a magazine), with a voluntary ugliness and impermanence, there is a total convergence between the message and the means, between the Information and design, as one transforms the other. In this case, the projects not only show an alternative approach but several, revealing the contrast between different views of the same project. The case of the Seattle Library is particularly illuminating: depending on the graphic approach, the distortion of the message makes the original project unrecognizable (Figure 8).

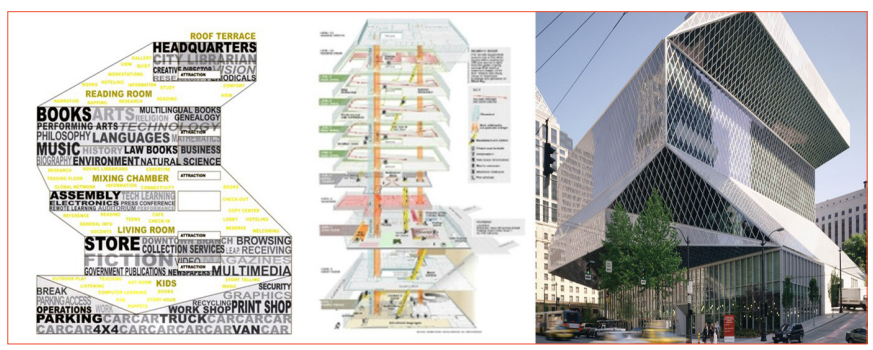

Figure 8. Different graphic approaches to the Seattle Library, 2002

\section{CONCLUSIONS}

The concept of "Design" and "Visualization" of information embraces the representation of architecture in theoretical and practical creative process. When the perception of a certain reality is based on its representation, information and visibility are a whole, leading to the necessary convergence between the story to be told and the way to do it, between the concept and the communicative strategy. The convergence of these two concepts encourages new approaches that provide an augmented vision of the data displayed and allow revisiting what we already know from an additional perspective, generating alternative visions of reality and implementing the creative possibilities of the subject of study. Therefore, the communicative strategy acquires the same relevance as the message, having the potential to strengthen and even transform it.

We talk about a two-dimensional exchange, called "Communication -Design", including the recording of the information as a necessary tool, as well. In the words of Bruce May, a renowned expert in communication in architecture: "Every new social condition demands and creates new visual forms for expressing the new ideas (...). This process where new ideas invent new visual languages and new visual languages invent new ideas is always happening in architectural and urban thinking."

\section{Notes}

1. Vitruve, and M. H. Morgan. Vitruvius: The Ten Books of Architecture. New York: Dover Publications, 1960.

2. Alberti, Leon Battista, and Angelo Poliziano. De Re Aedificatoria. Florentiae: Nicolau Laurentii, 1485.

3. Rem Koolhaas, Bruce Mau. Small, medium, large, extralarge: Office for Metropolitan Architecture. New York, NY: Monacelli Press, 1995.

4. Jennifer Sigler, "Rem Koolhaas". Index Magazine, 2000. http:// www.indexmagazine.com/interviews/rem_koolhaas.shtml

5. Rem Koolhaas, Content. Germany: Taschen, 2004.

6. Robert Venturi, Complexity and contradiction in Architecture. New York: The Museum of Modern Art. 1966.

7. R. Venturi, S. Izenour, D. Scott Brown, D. Aprendiendo de LaS Vegas (El simbolismo olvidado de la forma arquitectónica). Barcelona: G. Gili.1978.

8. Belén Butragueño, "Rem a los dos lados del espejo". P.hD. Dissertation, UPM. ETS. de Arquitectura de Madrid, 2015.

9. George Bateson, Steps to an Ecology of Mind. San Francisco: Jason Aronson Inc., 1972. 